\title{
HER-2, p53, p2I and hormonal receptors proteins expression as predictive factors of response and prognosis in locally advanced breast cancer treated with neoadjuvant docetaxel plus epirubicin combination
}

\author{
Daniel G Tiezzi*†1, Jurandyr M Andrade ${ }^{\dagger 1}$, Alfredo Ribeiro-Silva², \\ Fábio E Zola ${ }^{1}$, Heitor RC Marana ${ }^{1}$ and Marcelo G Tiezzi ${ }^{3}$
}

\begin{abstract}
Address: ${ }^{1}$ Department of Gynecology and Obstetrics - Breast Disease Division - Ribeirao Preto School of Medicine - HCFMRP- USP, Av Bandeirantes, 3900, 14048-900 Ribeirão Preto, São Paulo, Brazil, '2Department of Pathology - Ribeirao Preto School of Medicine - HCFMRP- USP, Ribeirao Preto, Brazil and ${ }^{3}$ Colaborating Pathologist from Presidente Prudente Laboratory of Pathology and Cytopathology, S/A, Presidente Prudente, Brazil

Email: Daniel G Tiezzi* - daniel.tiezzi@yahoo.com; Jurandyr M Andrade - andrade@fmrp.usp.br; Alfredo Ribeiro-Silva - arsilva@fmrp.usp.br; Fábio E Zola -fzola@hotmail.com; Heitor RC Marana - marana@keynet.com.br; Marcelo G Tiezzi - marcelotiezzi@uol.com.br

* Corresponding author †Equal contributors
\end{abstract}

Published: 26 February 2007

BMC Cancer 2007, 7:36 doi:10.1186/147I-2407-7-36

This article is available from: http://www.biomedcentral.com//47/-2407/7/36

(c) 2007 Tiezzi et al; licensee BioMed Central Ltd.

This is an Open Access article distributed under the terms of the Creative Commons Attribution License (http://creativecommons.org/licenses/by/2.0), which permits unrestricted use, distribution, and reproduction in any medium, provided the original work is properly cited.
Received: 5 October 2006

Accepted: 26 February 2007

\begin{abstract}
Background: Neoadjuvant chemotherapy has been considered the standard care in locally advanced breast cancer. However, about $20 \%$ of the patients do not benefit from this clinical treatment and, predictive factors of response were not defined yet. This study was designed to evaluate the importance of biological markers to predict response and prognosis in stage II and III breast cancer patients treated with taxane and anthracycline combination as neoadjuvant setting.
\end{abstract}

Methods: Sixty patients received preoperative docetaxel $\left(75 \mathrm{mg} / \mathrm{m}^{2}\right)$ in combination with epirubicin $\left(50 \mathrm{mg} / \mathrm{m}^{2}\right)$ in i.v. infusion in DI every 3 weeks after incisional biopsy. They received adjuvant chemotherapy with CMF or FEC, attaining axillary status following definitive breast surgery. Clinical and pathologic response rates were measured after preoperative therapy. We evaluated the response rate to neoadjuvant chemotherapy and the prognostic significance of clinicopathological and immunohistochemical parameters (ER, PR, p5I, p2I and HER-2 protein expression). The median patient age was 50.5 years with a median follow up time 48 months after the time of diagnosis.

Results: Preoperative treatment achieved clinical response in $76.6 \%$ of patients and complete pathologic response in $5 \%$. The clinical, pathological and immunohistochemical parameters were not able to predict response to therapy and, only HER2 protein overexpression was associated with a decrease in disease free and overall survival $(P=0.0007$ and $P=0.003)$ as shown by multivariate analysis.

Conclusion: Immunohistochemical phenotypes were not able to predict response to neoadjuvant chemotherapy. Clinical response is inversely correlated with a risk of death in patients submitted to neoadjuvant chemotherapy and HER2 overexpression is the major prognostic factor in stage II and III breast cancer patients treated with a neoadjuvant docetaxel and epirubicin combination. 


\section{Background}

Neoadjuvant or primary chemotherapy in large primary breast cancer has been used with the purpose of reducing tumor volume and promoting less aggressive surgery [1]. The disease's downstaging promotes higher conservative breast surgery rates and [2], in patients with objective clinical and pathological response, an increase in disease free and overall survival rates has been observed $[3,4]$. Otherwise, about $10 \%-35 \%$ of the patients do not benefit from this clinical approach $[5,6]$. The identification of this group of patients could avoid the chemotherapy side effects and point them toward other therapeutic alternatives.

Clinical and pathological criteria neither predict response to neoadjuvant chemotherapy nor accurately define tumor biology. Tumors with the same histological type, grade and clinical staging behave differently [7]. The current hypothesis is that morphologically similar tumors have distinct gene expression with distinct phenotypic profiles [8]. The development of new therapies directed at specific molecular expression has lead researchers to evaluate the usefulness of tumor protein expression as predictive factors of response.

Docetaxel, an agent that promotes microtubule stabilization and prevents depolymerization, can cause cell cycle arrest in the mitotic phase [9], and epirubicin, an anthracycline that interacts with topoisomerase II and blocks DNA transcription [10], have both currently been used in adjuvant and neoadjuvant breast cancer treatment. In a neoadjuvant setting, the combination of these two agents is among the most actively described chemotherapy regimens [11]. The study of the molecular tumor characteristics and effects of the taxane and anthracycline combination on protein modulation can provide information about the mechanism of action and play an important role in the individualization of neoadjuvant therapy.

We evaluated the expression of p53, p21 and HER-2 protein expression by immunohistochemistry (IHC) before and after neoadjuvant docetaxel plus epirubicin in locally advanced breast cancer patients and their relationship with clinical response and outcome.

\section{Methods}

Characteristics of patients and description of neoadjuvant therapy

Sixty women with a histological diagnosis of invasive breast cancer in incisional biopsy specimens were enrolled consecutively in the study. Inclusion criteria included patients with locally advanced epithelial breast cancer (AJCC clinical stage IIa, if T> $3 \mathrm{~cm}$; IIb and III), Karnofski performance status greater than $70 \%$ and age under 75 years. From February 2000 to December 2002, patients received treatment with taxane and anthracycline (docetaxel $75 \mathrm{mg} / \mathrm{m}^{2}$ and epirubicin $50 \mathrm{mg} / \mathrm{m}^{2}$, i.v. infusion, for one day every three weeks). No dose modification was allowed. The median cycle of chemotherapy was 3 cycles $(2-5)$ and the patients' median age was 50.5 years $(29-68)$. Thirty-one patients were at stage II and twenty-nine were at stage III. Presence of primary inflammatory breast carcinoma was an exclusion factor and invasive ductal carcinoma was the most common histological type (82.7\%). Sixteen tumors were grade I (23\%) and grade II and III was observed in $55.7 \%$ and $21.3 \%$ of the tumors, respectively. The median follow up time was 48 months $(24-69)$. Table 1 summarizes the patients' characteristics.

None of these patients had distant metastasis nor had they received prior therapy for cancer. Hepatic and renal function tests and blood cell count were carried out at each chemotherapy cycle, and no toxicity greater than 1 or 2 was observed. Table 2 describes the toxicity effects due to neoadjuvant chemotherapy. Chemotherapy was continued until tumors became operable in primary inoperable lesions or until breast conserving surgery could be performed in primary operable tumors. The patients with primary inoperable lesions who had no clinical response, defined after at least two cycles of chemotherapy, were subjected to a new incisional biopsy and given a second line of treatment consisting of breast radiation therapy (total dose of $50 \mathrm{~Gy}$ ) combined with a CMF chemotherapy regimen (cyclophosphamide $500 \mathrm{mg} / \mathrm{m}^{2}$, methotrexate $50 \mathrm{mg} / \mathrm{m}^{2}$ and 5 -fluoruracil $500 \mathrm{mg} / \mathrm{m}^{2}$ i.v. infusion, for 1 day, each 21/21 days) before definitive breast surgery. All procedures were carried out with the prior informed consent of the patient.

\section{Adjuvant treatment}

Adjuvant chemotherapy was offered to all patients. Regarding axillary lymph node status. The FEC regimen (5-fluoruracil $500 \mathrm{mg} / \mathrm{m}^{2}$, epirubicin $50 \mathrm{mg} / \mathrm{m}^{2}$ and cyclophosphamide $500 \mathrm{mg} / \mathrm{m}^{2}$ i.v. infusion, for 1 day, each $21 / 21$ days) was administered when more than three positive axillary lymph nodes (ALN+) were present after neoadjuvant treatment. The CMF regimen (cyclophosphamide $500 \mathrm{mg} / \mathrm{m}^{2}$, methotrexate $50 \mathrm{mg} / \mathrm{m}^{2}$ and 5 -fluoruracil $500 \mathrm{mg} / \mathrm{m}^{2}$ i.v. infusion, for 1 day, each $21 / 21$ days) was used if there were three or less ALN+. All patients received a total of nine chemotherapy cycles. Hormonal adjuvant therapy was offered to all patients with estrogen or progesterone receptor positive tumors. Patients received tamoxifen at $20 \mathrm{mg}$ PO for 60 months or until disease recurrence.

Adjuvant radiotherapy was performed in the residual breast parenchyma of all breast conserving surgery 
Table I: Characteristics of sixty breast cancer patients treated with neoadjuvant docetaxel plus epirubicin.

\begin{tabular}{|c|c|c|}
\hline Characteristcs & $\mathrm{n}=60$ (range) & $\%$ \\
\hline \multicolumn{3}{|l|}{ Age } \\
\hline Median & $50(29-67)$ & \\
\hline$\leq 45$ years & 18 & 30 \\
\hline$>45$ years & 42 & 70 \\
\hline \multicolumn{3}{|l|}{ Menopausal status } \\
\hline Pre & 28 & 46.6 \\
\hline Post & 32 & 53.4 \\
\hline Chemotherapy cycles (median) & $3(2-5)$ & \\
\hline \multicolumn{3}{|l|}{ Clinical Stage } \\
\hline IIA & 12 & 20 \\
\hline IIB & 19 & 31.7 \\
\hline IIIA & 8 & 13.3 \\
\hline IIIB & 18 & 30 \\
\hline IIIC & 3 & 5 \\
\hline \multicolumn{3}{|l|}{ Histology } \\
\hline Ductal & 49 & 81.7 \\
\hline Lobular & 4 & 6.7 \\
\hline Medular & 4 & 6.7 \\
\hline Outhers & 3 & 5 \\
\hline \multicolumn{3}{|l|}{ Histologic grade } \\
\hline 1 & 16 & 26.7 \\
\hline II & 32 & 53.3 \\
\hline III & 11 & 18.4 \\
\hline \multicolumn{3}{|l|}{ ER } \\
\hline Positive & 45 & 75 \\
\hline Negative & 15 & 25 \\
\hline \multicolumn{3}{|l|}{ PR } \\
\hline Positive & 32 & 53.3 \\
\hline Negative & 28 & 46.7 \\
\hline \multicolumn{3}{|l|}{ P53 protein } \\
\hline Positive & 17 & 28.3 \\
\hline Negative & 43 & 71.7 \\
\hline \multicolumn{3}{|l|}{ P2I protein } \\
\hline Positive & 20 & 33.3 \\
\hline Negative & 40 & 66.7 \\
\hline \multicolumn{3}{|l|}{ HER-2 } \\
\hline Positive & 11 & 18.3 \\
\hline Negative & 49 & 81.7 \\
\hline
\end{tabular}

$\mathrm{N}=$ number of patients; $E R$ = estrogen receptor; $\mathrm{PR}=$ progesterone receptor.

Table 2: Toxic effect incidences in sixty locally advanced breast cancer patients subjected to neoadjuvant docetaxel $\left(75 \mathrm{mg} / \mathrm{m}^{2}\right)$ and epirubicin $\left(50 \mathrm{mg} / \mathrm{m}^{2}\right)$ combination.

Toxicity (\%)

$\begin{array}{lr}\text { Alopecia } & 100 \\ \text { Nausea and vomiting } & 19.2 \\ \text { Neutropenia } & 11.5 \\ \text { Febrile neutropenia } & 3.8 \\ \text { Fever } & 5.7 \\ \text { Diarrhea } & 5.7 \\ \text { Mucositis } & 3.8 \\ \text { Allergic reactions } & 3.8 \\ \text { Asthenia } & 1.9 \\ \text { Headache } & 1.9\end{array}$


patients (50 Gy). Patients who underwent mastectomy received chest wall adjuvant radiotherapy if residual tumors were five centimeters or greater (at the highest pathological diameter) or if there was skin or muscle and chest wall invasion (50 Gy). The supraclavicular fossa was irradiated if there were four or more ALN+.

This study was approved by the local Ethics Committee in accordance with the ethical guidelines of the 1975 Declaration of Helsinki, revised 1983.

\section{Assessment of response to neoadjuvant chemotherapy}

The pathological and clinical assessment of response to neoadjuvant chemotherapy was taken. All surgical specimens from the definitive breast procedure were submitted for pathological evaluation and were classified as having a complete response (pCR) when no residual invasive carcinoma was seen.

The clinical stage and size of the primary tumor was recorded before treatment. The measurement of the primary tumor consisted of the product of its greatest diameter and its perpendicular diameter. The clinical response was evaluated at each cycle of chemotherapy and prior to definitive surgery on day 21 of the last cycle of chemotherapy according to the product of primary tumor diameters and the axillary clinical status, and was classified as a complete response (CR), partial response (PR), stable disease (SD), or progressive disease (PD) according to standard UICC (International Union Against Cancer) criteria [12]. CR was defined as the disappearance of all clinical evidence of the tumor including the axillary site; PR was defined as a reduction of $50 \%$ or more in the sum of the products of measured lesions or an estimated decrease in tumor size of at least $50 \%$, without the appearance of new lesions. Clinical down staging in axillary status was necessary; SD was defined as a decrease of less than $50 \%$ in the sum of the products of measured lesions, or an estimated decrease of less than $50 \%$ in lesion size or an increase of less than $25 \%$, without the appearance of new lesions. Any measured or estimated increase greater than $25 \%$ or the appearance of new lesions was defined as PD. No change in clinical axillary status was classified as SD regardless the change in primary tumor diameter. The patients were classified into two groups: the objective response group (OR), into which all patients classified as CR or PR were placed, and the no response group (NR), containing all patients classified as SD or PD.

\section{Immunohistochemistry}

All tissue samples had been routinely fixed in $4 \%$ neutral formalin and embedded in paraffin. Briefly, 3- $\mu \mathrm{m}$-thick sections were cut from paraffin blocks containing representative tumor samples. Paraffin sections were de-waxed in xylene, rehydrated through a series of graded alcohols, placed in $10 \mathrm{mM}$ citrate buffer and submitted to heat retrieval using a vapor lock for 40 minutes. After heating, the slides were allowed to cool to room temperature and briefly washed with Tris-buffered saline. Endogenous peroxidase activity was blocked with 3\% hydrogen peroxide in methanol for 5 minutes. Normal serum (Novostain Super ABC kit, Novocastra, Newcastle upon Tyne, UK) was used for 30 minutes in order to block non-specific immunoassaying. Immunohistochemical staining was performed using an avidin-biotin peroxidase system (Novostain Super ABC kit, Novocastra, UK). The following primary antibodies were incubated overnight at room temperature: ER (1:100, clone 6F11, Novocasta, UK), PR (1:100, clone 1A6, Novocasta, UK), p21 (1:50, clone 4D10, Novocastra, UK), HER-2 oncoprotein (1:300, clone CB11, Novocastra, UK), and p53 (1:100, clone DO-7, Novocastra, UK). Following washes in PBS, biotinylated universal secondary antibody (Novostain Super ABC kit, Novocastra, UK) was applied for 30 minutes. The sections were incubated with the avidin-biotin complex reagent (Novostain Super ABC kit, Novocastra, UK) for 30 minutes and developed with 3.3-diaminobenzidine tetrahydrochloride (DAB) in phosphate-buffered saline, $\mathrm{pH} 7.5$, containing $0.036 \%$ hydrogen peroxide for 5 minutes. Light Mayer's hematoxylin was applied as a counterstain. The slides were then dehydrated in a series of ethanols and mounted with Permount (Fischer, Fairlawn, NJ).

Cases of invasive ductal carcinoma, previously known to be positive for ER, PR, p21, p53 or HER-2, were used as positive controls. Negative controls for immunostaining were prepared by omission of the primary antibody.

\section{Scoring methods}

The cases were interpreted as positive for $\mathrm{p} 21$ if more than $5 \%$ of the tumors cells showed nuclear staining [13] and were considered positive to ER, PR and p53 protein expression if more than $10 \%$ of the tumors cells showed nuclear staining. HER-2 expression was scored according to the degree and the proportion of membrane staining according to HercepTest protocol $[14,15]$. HER-2 expression was negative with a score of 0 or $1+$. A score of 0 was defined as no staining or membrane staining in less than $10 \%$ of tumor cells. A score $1+$ comprised faint or partially-stained membrane in more of $10 \%$ of tumor tissue. Overexpression of HER-2 was scored as $2+$ when weak to moderate complete membrane staining was present in more than $10 \%$ of tumor cells. A score of $3+$ was interpreted as strong, complete membrane staining in more than $10 \%$ of the tumor.

\section{Study endpoints}

The primary goal was to test the correlation among p53, p21 and HER-2 protein expression and clinical response to neoadjuvant chemotherapy with docetaxel and epiru- 
bicin combination and to evaluate the impact of immunohistochemical and clinic-pathological parameters in disease free and overall survivals. A secondary goal was to study the ability of neoadjuvant taxane and anthracycline based chemotherapy to change tumor protein expression. We also studied the association between protein changes and the impact in disease free and overall survivals. The third objective was to evaluate the efficacy and toxicity of a neoadjuvant docetaxel and epirubicin combination. To test the treatment efficacy, we examined a clinical parameter of response and the type of surgery performed.

\section{Statistical analysis}

The McNemar test was used to evaluate the paired correlation between p53, p21 and HER-2 protein expression before and after neoadjuvant chemotherapy. Spearman's coefficient of rank correlation [16] was used to determine the correlation between axillary lymph node status and clinical response and to evaluate the correlation between clinical response and the risk of death in disease progression. The relationship between the clinical response with the patients' characteristics and histopathological patterns was evaluated with Fisher exact test and chi-squared test. The relationship between the number of chemotherapy cycles was analyzed with the Mann-Whitney test. The disease free survival (DFS) and overall survival (OS) were analyzed by the Kaplan-Meyer curve. MedCalc version 6.16.000 and Graphpad Prism version 4 software were used for the above statistical analyses. Multivariate analysis, to test the correlation between HER-2 protein expression, clinical response, axillary lymph node status and type of surgery performed with the risk of recurrence and death to disease progression, was performed using a nominal logistic fit with JMP 6.0 SAS software. The statistical significance was established as $p<0.05$.

\section{Results}

Neoadjuvant treatment, clinical response rate and surgery The objective clinical response (OR) was observed in 46 patients $(76.6 \%)$ treated with neoadjuvant chemotherapy. The clinical complete response rate (CCR) was $15 \%$ (nine patients) and the pathological complete response rate (pCR), defined as the absence of residual invasive carcinoma, was 5\% (three patients). Patients with stable and progressive disease were defined as no response patients (NR). The NR rate was $23.3 \%$ (14 patients) and progressive disease was observed in only two patients (3.3\%).

Surgery could be performed in fifty-nine patients $(98.3 \%)$. One patient with no response to the primary docetaxel plus epirubicin combination was submitted to second line chemo-radiation therapy. The tumor was resistant to second line treatment and she died due to metastatic disease progression before surgery could be performed. Breast conserving surgery could be performed in forty patients $(66.7 \%)$. Modified Radical Mastectomy was performed in patients for whom breast-conserving therapy was not indicated. Patients with OR had a higher breast conserving surgery rate than patients with NR (73.9\% vs. $35.7 \% ; p=0.03$, chi-square test).

Axillary lymph nodes were assessed histologicaly in 59 patients undergoing axillary node dissection. The median number of positive lymph nodes in patients with OR was $0(0-19)$ and in patients with NR was $3(0-25)$. There was a positive correlation between the lack of clinical response and the number of lymph node metastases $(p=$ 0.03; Sperman r). The response to neoadjuvant chemotherapy, the type of surgery performed, and the lymph node status in patients with OR and NR are summarized in Table 3.

\section{Clinical and histopathological characteristics and their relationship with clinical response}

We evaluated the association among clinical response, patients' characteristics (patient's age, menopausal status, number of chemotherapy cycles and clinical stage), and histological (histological grade) and immunohistochemical patterns (ER, PR, p53, p21 and HER-2 protein expression). The median age in patients with OR was 51.5 years (range $35-67$ ) and in the group of patients NR, the median age was 47.5 years ( $p=0.3$, Student $t$ test). In OR

Table 3: Surgery performed in sixty patients with locally advanced breast cancer subjected to neoadjuvant chemotherapy with docetaxel and epirubicin combination.

\begin{tabular}{|c|c|c|c|c|}
\hline & OR N (\%) & NR N (\%) & $P$ & Test \\
\hline Clinical Response & $46(76.7)$ & $14(33.3)$ & - & - \\
\hline \multicolumn{5}{|l|}{ Surgery } \\
\hline RS & $12(26)$ & $7(50)$ & & \\
\hline BCS & 34 (74) & $6(42.8)$ & & \\
\hline NS & 0 & I (7.2) & 0.03 & $x^{2}$ \\
\hline \multicolumn{5}{|l|}{ Node } \\
\hline Median (range) & $0(0-19)$ & $3(0-25)$ & 0.03 & Spearman $r$ \\
\hline
\end{tabular}

$\mathrm{OR}=$ objective response; $\mathrm{NR}=$ no response; $\mathrm{RS}=$ radical surgery; $\mathrm{BCS}=$ breast conserving surgery; $\mathrm{NS}$ = not submitted to surgery. 
group, 24 patients (52.1) and in NR group, 8 patients $(57.1 \%) \%)$ were classified as post menopausal status ( $p=$ 0.9; Chi-square test). The median number of chemotherapy cycles was three in both groups ( $p=0.4$; Mann-Whitney test) and there was no difference in clinical stage between the OR and NR groups of patients ( $p=0.78$; Chisquare test).

The estrogen receptor was positive in $72.7 \%$ of patients with OR and in $85.7 \%$ of NR patients ( $p=0.48$; Fisher's exact test) and the progesterone receptor was positive in $44 \%$ and $50 \%$ of patients with OR and NR, respectively ( $p$ $=0.76$, Fisher's exact test). There were no p53, p21 and HER-2 protein expression differences before chemotherapy between the OR and NR groups $(p=0.19, p=1.0$ and $p=0.43$; Fisher exact test, respectively). The histological grade was not able to predict clinical response $(\mathrm{p}=0.2$; Chi-square test). Table 4 shows the relationship between the clinical response and clinical, pathological and immunohistochemical patterns.

\section{Neoadjuvant chemotherapy and p53, p2I and HER-2 proteins expression change}

The expression of p53, p21 and HER-2 proteins was evaluated in biopsy specimens from 60 breast cancer patients before neoadjuvant chemotherapy. Because no or scarce residual tumor remained after chemotherapy, the evaluation of $\mathrm{p} 53$ and $\mathrm{p} 21$ protein expression was not possible in 6 patients specimens and, HER-2 protein expression was not carried out in 4 of the patient specimens.

Table 4: Clinical and histological features of sixty patients subjected to neoadjuvant chemotherapy with docetaxel plus epirubicin. Patients were divided according to clinical response as objective response (OR) and no response (NR) groups.

\begin{tabular}{|c|c|c|c|c|}
\hline & OR (n) & NR (n) & $P$ & Test \\
\hline \multicolumn{5}{|l|}{ Age } \\
\hline Median (range) & $5 I, 5(35-67)$ & $47,5(29-68)$ & 0.3 & Student $\mathrm{t}$ \\
\hline$\leq 45$ anos & 12 & 7 & & \\
\hline$>45$ anos & 35 & 7 & 0.1 & Fisher \\
\hline \multicolumn{5}{|l|}{ Menopausal Status } \\
\hline Post & 24 & 8 & & \\
\hline Pre & 22 & 6 & 0.9 & $x^{2}$ \\
\hline CT cycle (range) & $3(2-5)$ & $3(2-4)$ & 0.4 & Mann-Whitney \\
\hline \multicolumn{5}{|l|}{ CS } \\
\hline IIA & 8 & 4 & & \\
\hline IIB & 15 & 4 & & \\
\hline IIIA & 5 & 2 & & \\
\hline IIIB & 14 & 4 & & \\
\hline IIIC & 3 & 0 & 0.78 & $x^{2}$ \\
\hline \multicolumn{5}{|l|}{ Grade } \\
\hline I & 10 & 6 & & \\
\hline II & 27 & 5 & & \\
\hline III & 8 & 3 & 0.2 & $x^{2}$ \\
\hline \multicolumn{5}{|l|}{ ER } \\
\hline Positive & 32 & 12 & & \\
\hline Negative & 12 & 2 & 0.48 & Fisher \\
\hline \multicolumn{5}{|l|}{ PR } \\
\hline Positive & 20 & 7 & & \\
\hline Negative & 25 & 7 & 0.76 & Fisher \\
\hline \multicolumn{5}{|l|}{ ER/PR } \\
\hline Positive & 16 & 7 & & \\
\hline Negative & 22 & 7 & 0.75 & Fisher \\
\hline \multicolumn{5}{|l|}{ P53 } \\
\hline Positive & 16 & 2 & & \\
\hline Negative & 30 & 12 & 0.19 & Fisher \\
\hline \multicolumn{5}{|l|}{ P2I } \\
\hline Positive & 15 & 5 & & \\
\hline Negative & 31 & 9 & 1 & Fisher \\
\hline \multicolumn{5}{|l|}{ HER-2 } \\
\hline Positive & 10 & 1 & & \\
\hline Negative & 36 & 13 & 0.43 & Fisher \\
\hline
\end{tabular}

$\mathrm{OR}=$ objective response; $\mathrm{NR}=$ no response; $\mathrm{n}=$ number of patients; $\mathrm{CT}=$ chemotherapy; $\mathrm{CS}=$ clinical staging; Grade $=$ histological grade $(\mathrm{Bloom}$ Richardson); $E R$ = estrogen receptor; $P R=$ progesterone receptor. 
Positive p53 expression was identified in 18 patients (30\%) before and in 8 patients (14.5\%) after neoadjuvant chemotherapy. There was a significant reduction in p53 protein expression levels after chemotherapy $(p=0.039$; difference $13.2 \%$; McNemar test). The expression of p21 protein was positive in 13 patients $(21.6 \%)$ before and in 5 patients $(9.2 \%)$ after neoadjuvant chemotherapy. Neoadjuvant chemotherapy reduced p21 protein expression levels $(p=0.021$; difference $=14.81 \%$; McNemar test $)$. Positive HER-2 protein overexpression was observed in 11 patients (18.3\%) before chemotherapy. After neoadjuvant treatment, the overexpression of HER-2 protein was observed in seven patients $(12.5 \%)$. Neoadjuvant chemotherapy was not able to change HER-2 protein expression levels ( $p=0.12$; McNemar test). Table 5 shows immunohistochemical protein expression levels (p53, p21 and HER-2) before and after neoadjuvant chemotherapy.

\section{P2 I protein expression and its relationship with p53 and HER-2 protein expression}

We analyzed the relationship between p21 expression and p53 and HER-2 protein expression in pre-chemotherapy biopsy specimens. In forty patients with p53 negative tumors, we found 16 patients with $\mathrm{p} 21$ positive protein expression $(40 \%)$. In patients with positive p53 expression $(\mathrm{n}=16)$, we identified 4 patients with p21 positive tumors $(25 \%)$. The difference was not significant (Fisher's exact test; $\mathrm{p}=0.2$ ).

In eleven patients with HER-2 overexpression, we observed p21 positive protein expression in four patients (36.3\%) and, in 49 HER-2 negative patients, the p21 expression was positive in sixteen patients (32.6\%). There was no difference in the expression of $\mathrm{p} 21$ in such patients (Fisher's exact test; $\mathrm{p}=1.0$ ).

\section{Disease free and overall survival rates}

We evaluated the impact of clinical (age, clinical stage, clinical response, type of surgery), pathological (histological grade, axillary lymph node status) and immunohistochemical (ER, PR, p53, p21 and HER-2 protein expression) features on disease free and overall survival. We observed an inverse correlation between clinical response and the risk of death to disease $(p=0.02$; Spearman r). In a univariate analysis, only Her- 2 overexpression and two other factors related to clinical response were related to overall survival: the type of surgery (HR = $0.41,95 \%$ IC $=0.12$ to $0.96 ; p=0.042$ ) and the presence of extensive (more than six positive lymph nodes) residual disease in axillary lymph nodes $(\mathrm{HR}=0.35,95 \% \mathrm{IC}=$ 0.08 to $0.78 ; p=0.017)$.

In a multivariate analysis, only HER-2 overexpression was a predictive factor of DFS and OS $(p=0.0007$ and $p=$ 0.003 , respectively). The median time to DFS was 31 months $(\mathrm{HR}=0.35,95 \%$ IC $=0.08$ to $0.75 ; p=0.014)$ and the median time to OS was 40 months $(\mathrm{HR}=0.33,95 \%$ $\mathrm{IC}=0.06-0.75 ; p=0.016)$. Figures 1 and 2 show the Kaplan-Meyer curve for DFS and OS according to HER-2 protein expression, respectively.

\section{Discussion}

Neoadjuvant or induction chemotherapy is the current standard of care in locally advanced breast cancer [17]. Such treatment can reduce tumor volume, leading to less aggressive surgery and providing favorable local conditions for surgery in inoperable tumors $[1,2]$. About $80 \%$ of patients achieve a local benefit due to adequate tumor downstaging, however, the overall survival, when comparing neoadjuvant and adjuvant chemotherapy, is not influenced by the primary cytotoxic therapy [17].

We evaluated the response to neoadjuvant chemotherapy in 60 locally advanced breast cancer patients. The objective clinical response rate was $76.6 \%$, with a complete pathological response in $5 \%$ of patients. Breast conserving therapy was possible in forty patients $(66.6 \%)$ and in only one patient could the surgery not be performed due to the lack of response to neoadjuvant chemotherapy. Other studies reported a higher complete pathological response rate ranging from $8 \%$ to $10.5 \%$, using similar chemotherapy scheme $[16,18]$. However, the breast conserving surgery rate was higher in our study. They reported a breast conserving surgery rate of $16 \%$ and $15 \%$, respectively, in contrast to the study of Ganem et al who reported a breast conserving surgery rate of $69 \%$ [19]. This discordant result should be attributed to the enrollment of different number of patients with primary inoperable tumors among these studies.

The clinical and pathological response to neoadjuvant therapy in patients with large breast tumors has been

Table 5: Immunohistochemical patterns before and after neoadjuvant chemotherapy with docetaxel plus epirubicin in sixty breast cancer patients.

\begin{tabular}{|c|c|c|c|c|}
\hline & Pre-chemotherapy N (\%) & Post-chemotherapy N (\%) & $p$ & Dif. (\%) \\
\hline$p 53+$ & $18(30)$ & $8(14.5)$ & 0.039 & 13.2 \\
\hline$p 21+$ & $13(21.6)$ & $5(9.2)$ & 0.021 & $|4.8|$ \\
\hline HER-2 + & $11(18.3)$ & $7(12.5)$ & 0.12 & NS \\
\hline
\end{tabular}

$\mathrm{N}=$ number of patients; Dif. = difference between before and after chemotherapy - McNemar test; NS = not significant. 


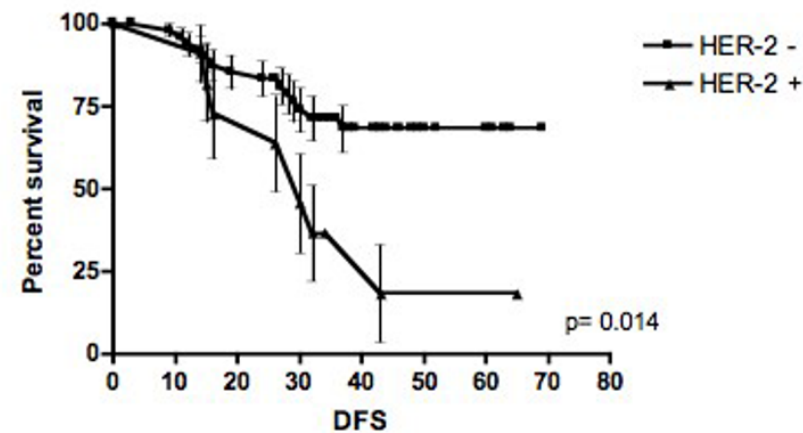

\section{Figure I}

Kaplan-Meyer curve for DFS in sixty patients subjected to Neoadjuvant chemotherapy with docetaxel and epirubicin according to HER-2 protein expression.

described as an independent prognostic factor $[3,4]$. We observed similar results. In our study, patients who achieved an objective response had a better prognostic than patients with stable or progressive disease after induction chemotherapy. The observation that patients with extensive lymph node metastasis after neoadjuvant therapy are more propitious to develop metastatic disease and die due to disease progression than patients with no extensive axillary metastasis supports the hypothesis that residual loco regional disease after neoadjuvant chemotherapy is a clinical marker of chemotherapy resistance.

The neoadjuvant therapy, considered to be an in vivo model to test chemotherapy sensitivity, is helpful to assess biological tumor behavior and to evaluate chemotherapy mechanisms of function and its relationship to drug resistance. In a previous study, we observed that the induction of apoptosis is an important predictor of response to chemotherapy in breast cancer and that such an event is influenced by protein tumor expression patterns [7]. In the present study, we evaluated the correlation among patients' characteristics, immunohistochemical expression of hormonal receptors (ER and PR), p53, p21 and HER-2 protein expression and the clinical and pathological response to a neoadjuvant combination of docetaxel and epirubicin. No parameter studied was able to predict response to neoadjuvant chemotherapy.

Changes in protein expression after neoadjuvant treatment have been reported $[20,21]$. Such observation suggests that chemotherapy can alter the tumor gene expression and that this event is a important point in drug sensitivity [7]. In the present study, we confirmed the reduction in p53 protein expression, as well in p21 pro-

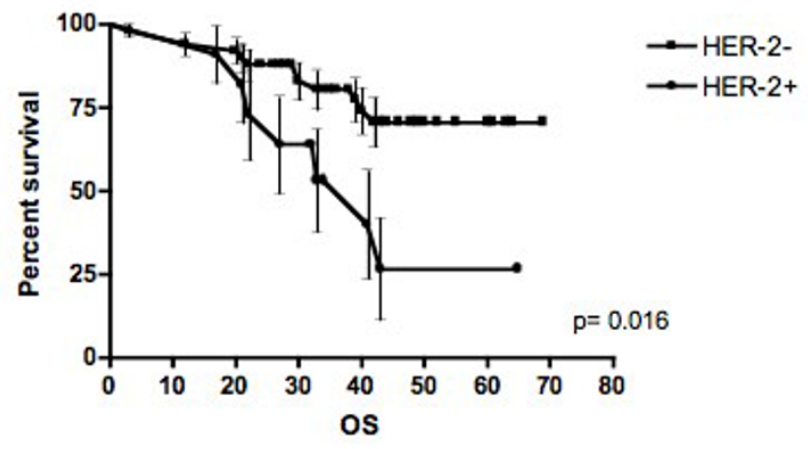

Figure 2

Kaplan-Meyer curve for OS in sixty patients subjected to neoadjuvant chemotherapy with docetaxel and epirubicin according to HER-2 protein expression.

tein expression, after neoadjuvant chemotherapy. However, the taxane and anthracycline combination in a neoadjuvant setting was not able to change HER-2 expression in patients with locally advanced breast carcinoma. The HER-2 stable phenotype during neoadjuvant chemotherapy was reported by others authors $[22,23]$.

Recent studies have been focused on the role of HER-2 as a predictive factor of response to neoadjuvant chemotherapy [24-26]. Zhang F et al and Fernández-Sánchez $M$ et al could not observe a correlation between HER-2 expression and the clinical or pathological response to neoadjuvant chemotherapy in patients with breast carcinoma treated with 5-fluoruracil, doxorubicin and cyclophosphamide combination (FAC). Otherwise, Learn PA et al demonstrated that the addition of docetaxel to anthracycline-based neoadjuvant chemotherapy improved clinical response rate in HER-2 positive breast cancer patients. In our study, the expression of the HER-2 protein was an independent prognostic factor in multivariate analysis; however, its expression was not able to predict the clinical and pathological primary tumor response.

We observed that the median time of disease free and the overall survival were 30 months and 41 months, respectively, in patients with HER-2 positive tumors. These patients achieved an overall survival rate of $25 \%$ after 48 months in contrast with $70 \%$ in patients with HER-2 negative expression. According to SEER estimation, patients with clinical stage III and grade 3 breast cancer (T3N1M0), with negative hormonal receptors subjected to no systemic therapy, have a ten year overall survival rate of $33.5 \%$ [27]. This observation leads us to offer alternative therapy with target agents to block the HER-2 activity for patients with HER-2 amplification. Recent studies have demonstrated a promising benefit of chemotherapy and 
immunotherapy (trastuzumab) combination regimens in a neoadjuvant setting in patients with HER-2 amplification breast cancer $[28,29]$.

\section{Conclusion}

We have concluded that the clinical response to neoadjuvant chemotherapy is a relevant prognostic factor in patients with locally advanced breast cancer treated with a neoadjuvant docetaxel and epirubicin combination. The value of biological makers as predictive factor of response to neoadjuvant therapy is still not clear. Advanced breast tumors exhibit a polyclonal population and the high number of genetic dysfunction limits the use of specific markers in clinical practice. Future directions are going to be based on multiple gene expression patterns, called genetic signatures. Recent publications have shown a positive relationship between a gene expression signature and a complete pathological response to primary chemotherapy $[30,31]$.

On the other hand, HER-2 overexpression is the major relevant phenotype in breast cancer progression regardless the clinical response to neoadjuvant chemotherapy. HER2 overexpression in primary tumor is a stable phenotype during neoadjuvant chemotherapy and is a marker of distant disease progression and death.

\section{Competing interests}

The author(s) declare that they have no competing interests.

\section{Authors' contributions}

DGT participated in the design of the study, recruitment and treatment of patients, draft the manuscript and performed statistical analysis. JMA participated in the design and coordination of the study and helped to draft the manuscript. ARS and MGT performed the immunohistochemical analysis. FEZ and HRCM participated in the treatment of patients and helped with the design of the study. All authors read and approved the final manuscript.

\section{Acknowledgements}

The authors thank Ms. Deisy Mara da Silva for excellent technical assistance. This research was supported by a grant from Fundação de Amparo ao Ensino, Pesquisa e Assistêcia (FAEPA) do HCFMRP - USP and Coordenação de Aperfeiçoamento de Pessoal de Nível Superior (CAPES), Brazil.

\section{References}

I. Beriwal S, Schwartz GF, Komarnicky L, Garcia-Young JA: Breastconserving therapy after neoadjuvant chemotherapy: longterm results. Breast / 2006, I 2(2): 159-164.

2. Fisher B, Brown A, Mamounas E, Wieand S, Robidoux A, Margolese RG, Cruz AB Jr., Fisher ER, Wickerham DL, Wolmark N, DeCillis A, Hoehn JL, Lees AW, Dimitrov NV: Effect of preoperative chemotherapy on local-regional disease in women with operable breast cancer: findings from National Surgical Adjuvant Breast and Bowel Project B-18. I Clin Oncol 1997, I 5(7):2483-2493.
3. Fisher B, Bryant J, Wolmark N, Mamounas E, Brown A, Fisher ER, Wickerham DL, Begovic M, DeCillis A, Robidoux A, Margolese RG, Cruz AB Jr., Hoehn JL, Lees AW, Dimitrov NV, Bear HD: Effect of preoperative chemotherapy on the outcome of women with operable breast cancer. J Clin Oncol 1998, 16(8):2672-2685.

4. Amat S, Abrial C, Penault-Llorca F, Delva R, Bougnoux P, Leduc B, Mouret-Reynier MA, Mery-Mignard D, Bleuse JP, Dauplat J, Cure H, Chollet P: High prognostic significance of residual disease after neoadjuvant chemotherapy: a retrospective study in 710 patients with operable breast cancer. Breast Cancer Res Treat 2005, 94(3):255-263.

5. Bonadonna G, Veronesi U, Brambilla C, Ferrari L, Luini A, Greco M, Bartoli C, Coopmans de Yoldi G, Zucali R, Rilke F, et al.: Primary chemotherapy to avoid mastectomy in tumors with diameters of three centimeters or more. J Natl Cancer Inst 1990, 82(19): I539-1545.

6. Schwartz GF, Meltzer AJ, Lucarelli EA, Cantor JP, Curcillo PG 2nd: Breast conservation after neoadjuvant chemotherapy for stage II carcinoma of the breast. J Am Coll Surg 2005, 20 I(3):327-334.

7. Tiezzi DG, De Andrade JM, Candido dos Reis FJ, Marana HR, RibeiroSilva A, Tiezzi MG, Pereira AP: Apoptosis induced by neoadjuvant chemotherapy in breast cancer. Pathology 2006, 38(I):2I-27.

8. Hennessy BT, Gonzalez-Angulo AM, Hortobagyi GN: Individualization of neoadjuvant therapy for breast cancer according to molecular tumor characteristics. Nat Clin Pract Oncol 2005, 2(12):598-599.

9. Morse DL, Gray H, Payne CM, Gillies RJ: Docetaxel induces cell death through mitotic catastrophe in human breast cancer cells. Mol Cancer Ther 2005, 4(10): I 495-1504.

10. Sinha BK, Politi PM: Anthracyclines. Cancer Chemother Biol Response Modif 1990, I I:45-57.

II. Goble S, Bear HD: Emerging role of taxanes in adjuvant and neoadjuvant therapy for breast cancer: the potential and the questions. Surg Clin North Am 2003, 83(4):943-97I.

12. Hayward JL, Carbone PP, Heusen JC, Kumaoka S, Segaloff A, Rubens $\mathrm{RD}$ : Assessment of response to therapy in advanced breast cancer. Br J Cancer 1977, 35(3):292-298.

13. Allal AS, Gervaz P, Brundler MA: Cyclin DI, cyclin E, and p2I have no apparent prognostic value in anal carcinomas treated by radiotherapy with or without chemotherapy. $\mathrm{Br} J$ Cancer 2004, 9 I (7): I 239-1244.

14. Jacobs TW, Gown AM, Yaziji H, Barnes MJ, Schnitt SJ: Specificity of HercepTest in determining HER-2/neu status of breast cancers using the United States Food and Drug Administrationapproved scoring system. J Clin Oncol 1999, 17(7): 1983-1987.

15. Jacobs TW, Gown AM, Yaziji H, Barnes MJ, Schnitt SJ: Comparison of fluorescence in situ hybridization and immunohistochemistry for the evaluation of HER-2/neu in breast cancer. J Clin Oncol 1999, I7(7): 1974-1982.

16. Ramaswamy B, Povoski SP, Rhoades C, Allen J, Hauger M, Young D, Burak W, Farrar W, Yee L, Kendra K, Somasundaram S, Orlowski RZ, Shapiro CL: Phase II trial of neoadjuvant chemotherapy with docetaxel followed by epirubicin in stage II/III breast cancer. Breast Cancer Res Treat 2005, 93(I):67-74.

17. Kaufmann M, Hortobagyi GN, Goldhirsch A, Scholl S, Makris A, Valagussa $P$, Blohmer JU, Eiermann W, Jackesz R, Jonat W, Lebeau $A$, Loibl S, Miller W, Seeber S, Semiglazov V, Smith R, Souchon R, Stearns $V$, Untch M, von Minckwitz G: Recommendations from an international expert panel on the use of neoadjuvant (primary) systemic treatment of operable breast cancer: an update. J Clin Oncol 2006, 24(1 2): 1940-1949.

18. Han S, Kim SB, Kang SS, Noh WC, Paik NS, Chang ES, Kim JR, Lim $\mathrm{SH}$, Park HS: A phase II study of neoadjuvant docetaxel plus doxorubicin (KBCS-OI) in stage II, III breast cancer. Breast Cancer Res Treat 2006, 98(I):57-61.

19. Ganem G, Tubiana-Hulin M, Fumoleau P, Combe M, Misset JL, Vannetzel JM, Bachelot T, De Ybarlucea LR, Lotz V, Bendahmane B, Dieras V: Phase II trial combining docetaxel and doxorubicin as neoadjuvant chemotherapy in patients with operable breast cancer. Ann Oncol 2003, I 4(II): 1623-1628.

20. Bottini A, Berruti A, Bersiga A, Brunelli A, Brizzi MP, Marco BD, Cirillo F, Bolsi G, Bertoli G, Alquati P, Dogliotti L: Effect of neoadjuvant chemotherapy on Ki67 labelling index, c-erbB-2 
expression and steroid hormone receptor status in human breast tumours. Anticancer Res 1996, 16(5B):3105-3110.

21. Bottini A, Berruti A, Bersiga A, Brizzi MP, Brunelli A, Gorzegno G, DiMarco B, Aguggini S, Bolsi G, Cirillo F, Filippini L, Betri E, Bertoli G Alquati P, Dogliotti L: p53 but not bcl-2 immunostaining is predictive of poor clinical complete response to primary chemotherapy in breast cancer patients. Clin Cancer Res 2000, 6(7):275I-2758.

22. Stearns $V$, Singh B, Tsangaris T, Crawford JG, Novielli A, Ellis MJ, Isaacs C, Pennanen M, Tibery C, Farhad A, Slack R, Hayes DF: A prospective randomized pilot study to evaluate predictors of response in serial core biopsies to single agent neoadjuvant doxorubicin or paclitaxel for patients with locally advanced breast cancer. Clin Cancer Res 2003, 9(I):124-133.

23. Taucher S, Rudas M, Mader RM, Gnant M, Sporn E, Dubsky P, Roka S, Bachleitner T, Fitzal F, Kandioler D, Wenzel C, Steger GG, Mittlbock M, Jakesz R: Influence of neoadjuvant therapy with epirubicin and docetaxel on the expression of HER2/neu in patients with breast cancer. Breast Cancer Res Treat 2003, 82(3):207-213.

24. Zhang F, Yang Y, Smith T, Kau SW, McConathy JM, Esteva FJ, Kuerer HM, Symmans WF, Buzdar AU, Hortobagyi GN, Pusztai L: Correlation between HER-2 expression and response to neoadjuvant chemotherapy with 5-fluorouracil, doxorubicin, and cyclophosphamide in patients with breast carcinoma. Cancer 2003, 97(7): I758-I765.

25. Fernandez-Sanchez M, Gamboa-Dominguez A, Uribe N, Garcia-Ulloa AC, Flores-Estrada D, Candelaria M, Arrieta O: Clinical and pathological predictors of the response to neoadjuvant anthracycline chemotherapy in locally advanced breast cancer. Med Oncol 2006, 23(2): $17 \mid-183$.

26. Learn PA, Yeh IT, McNutt M, Chisholm GB, Pollock BH, Rousseau DL Jr., Sharkey FE, Cruz AB, Kahlenberg MS: HER-2/neu expression as a predictor of response to neoadjuvant docetaxel in patients with operable breast carcinoma. Cancer 2005, I 03(II):2252-2260.

27. Ravdin PM, Siminoff LA, Davis G], Mercer MB, Hewlett J, Gerson N Parker HL: Computer program to assist in making decisions about adjuvant therapy for women with early breast cancer. J Clin Oncol 200I, I 9(4):980-99I.

28. Ahluwalia MS, Daw HA: Neoadjuvant therapy with trastuzumab, paclitaxel and epirubicin for HER-2-positive operable breast cancer. J Clin Oncol 2005, 23(30):7759-60; author reply 7760-I.

29. Montemurro F, Aglietta M: Incorporating trastuzumab into the neoadjuvant treatment of HER2-overexpressing breast cancer. Clin Breast Cancer 2005, 6(I):77-80.

30. Ayers M, Symmans WF, Stec J, Damokosh Al, Clark E, Hess K, Lecocke M, Metivier J, Booser D, Ibrahim N, Valero V, Royce M, Arun B, Whitman G, Ross J, Sneige N, Hortobagyi GN, Pusztai L: Gene expression profiles predict complete pathologic response to neoadjuvant paclitaxel and fluorouracil, doxorubicin, and cyclophosphamide chemotherapy in breast cancer. J Clin Oncol 2004, 22( I 2):2284-2293.

31. Thuerigen $O$, Schneeweiss A, Toedt G, Warnat P, Hahn M, Kramer H, Brors B, Rudlowski C, Benner A, Schuetz F, Tews B, Eils R, Sinn HP, Sohn C, Lichter P: Gene expression signature predicting pathologic complete response with gemcitabine, epirubicin, and docetaxel in primary breast cancer. J Clin Oncol 2006, 24(I 2): $1839-1845$.

\section{Pre-publication history}

The pre-publication history for this paper can be accessed here:

http://www.biomedcentral.com/1471-2407/7/36/prepub
Publish with Bio Med Central and every scientist can read your work free of charge

"BioMed Central will be the most significant development for disseminating the results of biomedical research in our lifetime. "

Sir Paul Nurse, Cancer Research UK

Your research papers will be:

- available free of charge to the entire biomedical community

- peer reviewed and published immediately upon acceptance

- cited in PubMed and archived on PubMed Central

- yours - you keep the copyright
BioMedcentral 